\title{
Corrigendum
}

\section{A Critical Examination of the Internal Consistency of Competencies Assessed Across Multiple Methods - Corrigendum}

Paul Englert, Duncan J. R. Jackson and Marco van Gelderen doi: http://dx.doi.org/10.1375/ajop.4.1.11, Published by Australian Academic Press

On page 11 the author affiliations should be as follows:

Paul Englert ${ }^{1}$, Duncan J. R. Jackson ${ }^{2}$ and Marco van Gelderen ${ }^{3}$

${ }^{1}$ Psytech International Limited, Bedfordshire, United Kingdom

${ }^{2}$ College of Business Administration, The University of Seoul

${ }^{3}$ Faculty of Economics and Business Administration, Department of Management \& Organization, VU Centre for Entrepreneurship, The Netherlands

\section{Reference}

Englert P, Duncan JJR and van Gelderen M, A Critical Examination of the Internal Consistency of Competencies Assessed Across Multiple Methods The Australian and New Zealand Journal of Organisational Psychology, 4(1), 11-19. 